\title{
Novel role for specialist nurses in managing diabetes in the community
}

\author{
Mary MacKinnon, R Malcolm Wilson, C A Hardisty, J D Ward
}

\begin{abstract}
To develop care of diabetes further a specialist nurse established contact with general practices in Sheffield Health District and identified difficulties in providing a service for diabetics. One hundred and thirty practices were visited, and full data were collected from 104. Each practice agreed to establish a register of diabetics, and information and support were subsequently provided to help in developing services. In collecting information from each practice the nurse covered specific points on staff, facilities, and organisation.

Over two years the service offered in 60 practices considerably improved, allowing a minimum standard of diabetic care to be achieved. This allowed coordinated and effective referral of certain patients from hospital diabetic clinics and improved services to those not attending any clinics.
\end{abstract}

\section{Introduction}

The tradition of the large diabetic clinic serving a district creates deficiencies, not the least being that a large proportion of diabetic patients do not attend. Over the past 15 years several methods of sharing care or collaboration between hospital and general practice have been reported. Thorn established the principle of "miniclinics" in Wolverhampton, initially covering 14 practices.' The community care service for diabetics in Poole took two years to become operational and required intensive preparation and dedication from the interested physician and local general practitioners. To facilitate the scheme computer programs were developed to store clinical data and organise clinic visits and screening. Continued efforts have established this as an effective scheme. ${ }^{2}$

In Sheffield over 1000 patients were discharged from a diabetic clinic over three years. A nurse was available to visit practices, but the scheme was not coordinated effectively, and no attention was paid to the problems many practices faced. As a result many patients were either not being seen regularly by anybody or under the impression that their diabetes was cured. ${ }^{3}$ In Cardiff, a randomised trial compared hospital care and general practitioners' services, but the doctors were given no special support, and this attempt again highlighted the need for planning, collaboration, preparation, and the provision of suitable support. ${ }^{+}$Considerable personal collaborative contact is essential in any scheme aimed at improving services for diabetics in a community. Sending a questionnaire to a large number of general practitioners does not develop useful links. ${ }^{5}$ In Ipswich a training programme was available, cooperation booklets were produced, and considerable back up was given regarding retinopathy screening. An efficient register was kept ${ }^{6}$ but again a further report showed that a high proportion of patients in this scheme did not receive adequate care.

In many of these studies criticism of the general practitioner is implied by the fact that so many patients were not being seen or were not receiving appropriate care and screening for the complications of diabetes. Such criticism, however, denies the fact that many difficulties arise in developing a service for diabetics in which regular supervision and education of patients are at the centre of management. Moreover, many practices are being encouraged to provide other medical services. We set up this study to identify the practical difficulties that hinder the development of a minimum standard of care of diabetics in general practice.

\section{Subjects and methods}

Sheffield has a stable population of about 550000 . Four specialists in diabetes provide care for adults in two main hospitals in the district, there being separate services for children in two paediatric departments.

We compiled a list of practices from the family practitioner list and informed the family practitioner committee of the project. All practices were located, mapped, and coded. The city was divided into sectors for easy recognition and to enable practices to be visited in groups. A study group of practice nurses had been formed by the specialist nurse two years previously, and practices employing nurses were identified. Discussions were held with the specialists in diabetes in the city, and a letter from the specialist nurse and doctors was sent to all general practitioners introducing the concept of the survey and offering help to develop services for diabetics. At the same time other important groups were informed of the project: the local medical committee, senior nursing administration, chiropodists, dietitians, and the local branch of the British Diabetic Association.

The nurse visited each practice for discussions with one or more general practitioners. Other members of the staff were included whenever possible. Discussion in each practice followed a defined course. It included discussion of numbers of patients in the practice, geography, staff, facilities, organisation, and other services provided. Existing services for diabetics and problems encountered in their provision were examined. Where no service existed a whole package was given. This included updates on diabetes, ideas towards a protocol, answers to questions, and the offer of help.

Most practices requested follow up visits, this in itself indicating the value that they attached to the discussions and to the help that was being offered. Particular help requested was, for example, with an initial audit and how best to identify the diabetic population. Follow up visits also included the nurse 
being present and giving support at sessions until the practice staff gained confidence.

\section{Results}

One hundred and thirty practices were visited, and complete information is presented from 104 practices. Of these, 42 practices consisted of groups of three or more doctors; 31 consisted of two doctors; and 31 were singlehanded practices, in which potentially there were additional problems in developing a service. Eighteen practices had branch surgeries, and in many instances patients living near the branch surgery were reluctant to attend sessions for diabetics at the main surgery. In smaller practices poor buildings and lack of staff and facilities did not allow practitioners to improve their services.

All practices used laboratory facilities for estimates of blood glucose concentrations when required. Fourteen practices that already provided a service for diabetics used visually read blood glucose strips or meters, but there was clearly a need for updating and further education on the use and maintenance of such equipment.

All practices had most of the equipment required to run a service for diabetics. The main difficulties were inaccurate weighing scales, absence of a height gauge, expired equipment for testing blood and urine, and no chart to assess visual acuity. Servicing of sphygmomanometers and ophthalmoscopes was also required in some practices. Advice was given on the type of equipment and where to obtain supplies or servicing at a low cost. Computers or video facilities, or both, were available in six practices. These items of equipment have recently become more widely available.

At the beginning of the survey only 14 practices had attempted to review the feet of diabetics and identify those at risk. Two years later, however, 60 practices aimed to provide such a service. All practices indicated great concern about the provision of chiropody services for their patients who were not attending hospital clinics.

As no community dietitian was available practice nurses were taught simple dietary guidelines for patients with non-insulin dependent diabetes. They were encouraged to "personalise" their advice after receiving daily meal diaries. Simple information was provided to help them. Practice staff also required help and information on food, fluid, and general advice during illness for both non-insulin dependent and insulin dependent diabetics. Referral information about the district dietetic services was given with the name of the chief dietitian in each hospital. Fourteen practices could supply dietary advice at the beginning of the survey; after help from the nurse specialist 60 were able to supply this advice.

There were major concerns about screening of eyes. Fifteen practices carried out routine funduscopy through dilated pupils at the start of the study. The major worries were the small numbers of patients and consequent lack of skill; insufficient time especially in larger practices; the safety of mydriatics and the precipitation of acute glaucoma; and organisation of screening. Most general practitioners in discussion expressed the need for a training scheme; a few thought that a clinical assistantship would be useful. Eighty five practices either periodically suggested examination by the optician or gave no advice. There was no system of checking that eye screening or advice had been given in the 85 practices. A system was subsequently introduced, however, in the 51 practices providing a service. The whole question of visual problems and screening for diabetic retinopathy was discussed in all practices by the specialist nurse, who supplied the following: correctly set up Snellen charts; information about ophthalmoscopes; organisation and recall systems; and advice about mydriatics.

Only seven practices were concerned with the financial implications of providing or improving services for diabetics, so this did not seem to be a major consideration.

Care, surveillance, and education provided for diabetics in 104 practices at beginning and end of study

\begin{tabular}{lcc}
\hline & 1985 & 1987 \\
\hline Practice nurse employed & 20 & 59 \\
Register, recall, follow up & 16 & 82 \\
Service for diabetics & 16 & 60 \\
Education for diabetics & 13 & 57 \\
Screening for retinopathy & 15 & 51
\end{tabular}

After two years 60 practices provided services a differing standards for diabetic patients, and the table summarises these improvements. There were obvious improvements in the practices' awareness and care of diabetic patients where good communication and working relationships were well developed.

\section{Discussion}

Each general practice is an individual entity providing flexible treatment and preventive services to its population. Any new system must be organised according to the availability of facilities and the needs of patients; this is particularly so for diabetics. Unlike in the hospital service administrative, organisational, and laboratory support is not near at hand. In attempting to improve services to diabetic patients whether in hospital or in general practice considerable liaison between doctors and nurses is needed. This can be provided by a nurse specialising in care for diabetics. During our study, with the encouragement of the local family practitioner committee, practice premises improved, staff numbers increased, and motivation increased to provide adequate clinical care of and services for diabetics.

The fundamental need in a service for diabetics in the community is the provision of a register of diabetics. Our major achievement has been to establish such a register, which, coupled with the known patients attending hospital clinics, has begun to approach total ascertainment of the diabetic population. In any large city overlapping boundaries (geographical, district, city, family practitioner committee, and practice) may cause problems of follow up and continuity of care. In Sheffield 4000 patients' details are now available on practice registers. Simply constructed, these registers have proved invaluable in finding out where patients are seen, if at all. Education on diabetes and clinical review can be missed when patients have multiple medical problems or have been referred to a doctor with no special interest in diabetes. A named receptionist in each practice (including the branch surgery) in collaboration with the practice nurse can keep the register of diabetics and recall system up to date.

Copies of the registers from individual practices collected by the specialist nurse will be entered into a district computer system. In this way the patients of general practitioners who are not providing a service can be identified and offered clinical and screening services through the hospital services. Eventually, establishing a full time centre purely for diabetics will allow the coordination of such aspects of care.

Obviously the role of the coordinating nurse is important, but many practice nurses are also intimately concerned in organising and running clinical services 
for diabetics in general practice. ${ }^{8}$ As with the general practitioners themselves the danger of isolation from discussion and information about clinical management is ever present, and general practitioners and practice nurses should have regular update meetings. As we have shown, the range of help required by general practitioners and nurses is considerable. Most seemed unaware of facilities and services provided by the British Diabetic Association. The folder on diabetes produced by the Royal College of General Practitioners was not commonly used, most practices preferring the opportunity to discuss problems with the specialist nurse. Certainly the study highlighted the need for continuing and adequate communications between hospital and general practice with a sharing of clinical information, particularly when patients are attending hospital whether in specialist diabetes clinics or not. Information and help should be provided for reception and office staff in practices. Their role in contacting patients, organising services, and developing care for diabetics in general practice is important.

People with diabetes require information, support, and surveillance. Provision of services to the diabetic population in a large city can be considerably improved with a positive approach and the help of a specialist nurse.

We thank Servier Laboratories UK for funding this project; the general practitioners, practice nurses, and staff in Sheffield, who continue to participate in expanding their services; Dr M B Collins and partners and Drs P G Newrick and $A M$ Jennings for their support and advice; and Heather Gibson for clerical help:

1 Thorn PA, Russell RG. Diabetic clinics today and tomorrow: mini-clinics in general practice. BrMed 7 1973;ii:534-6.

2 Hill RD. Community care for diabetics in the Poole area. $\mathrm{Br} \mathrm{Med} \mathcal{J} 1976$; $1137-9$.

3 Wilks E, Lawton EE. The diabetic, the hospital and primary care. $\mathcal{I} R$ Coll Gen Pract 1980;30:199-206.

4 Hayes TM, Harris J. Randomised controlled trial of routine hospital clinic care versus routine general practice care for type II diabetics. $\mathrm{Br}$ Med $\mathrm{J}$ 1984;289:728-30.

5 Mellor JG, Samanta A, Blanford RL, Burdon AC. Questionnaire survey of diabetic care in general practice in Leicestershire. Health Trends 1985;17: 61-3.

6 Day JL. Part 1. The organisation of diabetic care. Hospital Update 1980;6: $1177-83$

Day JL, Humphreys H, Alban-Davis H. Problems of comprehensive shared diabetes care. Br Med f 1987;294:1590-2.

8 MacKinnon M. The role of nurses in general practice. Practical Diabetes 1986;3:232-4.

(Accepted 19 fune 1989)
Acquired immune deficiency syndrome

AIDS: Principles, Practices, and Politics. Ed I B Corless, $M$ PittmanLindeman. (Pp xvii +252 ; £58.) Washington: Hemisphere Publishing, 1988. ISBN 0-89116-795-1.

AIDS: the HIV Myth. J Adams. (Pp xii +244 ; 112.95.) London: Macmillan, 1989. ISBN $0-333$. 48930-6.

HIV Detection by Genetic Engineering Methods. Ed P A Luciw, K S Steimer. (Pp xiii +301 ; figs; $\$ 119.50$.) New York:

\section{Addiction}

E.URO Reports and Studies 108. "Alcohol and the Mass Media." J Partanen, M Montonen. (Pp 73; Sw frs 8 paperback.) Copenhagen: World 8 paperback.) Copenhagen: World 890-1274-9.

Pssst... a Really Useful Guide to Alcohol. A Maryon Davis. (Pp viii +152 ; figs; $£ 3.99$ paperback.) London: Pan Books, 1989. ISBN 0-330-31109-3.

\section{Allergy}

Allergy: the Facts. R Davies, S Ollier. (Pp viii + 200; figs; $\$ 4.95$ paperback.) Oxford: Oxford University Press, 1989. ISBN 0-19-261858-X

\section{Alternative medicin}

Medicine in Rural China: a Personal Account. C C Chen, in collaboration with F M Bunge. (Pp xix +218; figs; $\$ 35$.$) Berkeley: University of$ California

Standard Acupuncture Nomenclature. Part 2. World Health Organisation. (Pp 17; paperback, price not stated.) Manila: World Health Organisation Regional Office for the Western Pacific, 1988.

\section{Anaesthesia}

Anaesthesia and Malignant Disease. J Filshie, D S Robbie. (Pp xv+303; ISBN 0-7131-4553-6.

Anatomy

Anatomy and Human Movement: StrucField, R Soames. (Pp iv +891 ; figs;
£60.) Oxford: Heinemann Medical, 1989. ISBN 0-433-00032-5.

\section{Blood pressure}

The BMA Family Doctor Guides. "High Blood Pressure." P Semple. Series editor T Smith. (Pp 95; figs; $£ 2.99$ paperback.) London: Equation in association with the British Medica Association, 1989. ISBN 1-85336 053-8.

Calcium in Essential Hypertension. Ed K Aoki, E D Frohlich. (Pp xviii +675 ; $\$ 150$.) Tokyo: Academic Press, 1989 ISBN 0-12-058845-5.

\section{Cardiovascular diseases}

Cardiovascular Clinics. "Heart Disease in Women." Ed P S Douglas. Series editor A N Brest. (Pp xx+316; figs; colour plate; $£ 50$.) Philadelphia: colour plate; 550 .) Philadelph
Davis, 1989. ISBN 0-8036-2751-3.

Developments in Cardiovascula Medicine. Vol 92. "Electrocardiography and Cardiac Drug Therapy." Ed V Hombach, $\mathrm{H}$ H Hilger, $\mathrm{H}$ L Kennedy. (Pp xiii+369; figs; £68.) Dordrecht: Kluwer, 1989. Distributed by MTP Press. ISBN 0-89838-395-1.

\section{Cardiovascular system}

The Circulation in the Female from the Cradle to the Grave. Ed J Ginsburg. (Pp xv+174; figs; £38.) Carnforth: (Pp xv+174; figs; 338 .) Carnforth:
Parthenon, 1989. ISBN 0-94081368-8.

\section{Computers in medicine}

Practical Guides for General Practice. 7. "Computers: a Guide to Choosing and "Computers: a Guide to Choosing and Using." A Willis, T Stewart. (Pp iii+
138; figs; $£ 6.95$ paperback.) Oxford: 138; figs; $£ 6.95$ paperback.) Oxford:
Oxford University Press, 1989. ISBN Oxford University

\section{Disabled/handicapped people}

Dictionary of Mental Handicap. M P Lindsey. (Pp vi +345 ; 335 .) London: Routledge, 1989. ISBN 0-41502810-8.

\section{Endocrinology}

Calcium Homoeostatis: Hypercalcemi and Hypocalcemia G R Mundy. ( $P$ vii +248 ; figs; £49.95.) London Dunitz, 1989. ISBN 0-948269-67-7.

Pineal Research Reviews. Vol 7. Ed R J Reiter. (Pp xiii+234; \$120) New
York: Liss, 1989. Distributed by John Wiley and Sons. ISBN 0-8451-3606-2.

Environmental and public health

Architectural Design and Indoor Microbial Pollution. Ed R B Kundsin. Pp x +317; figs; £37.50.) New York: Oxford University Press, 1989. ISBN 0-19-504436-3.

Engineered Organisms in the Enviro ment. [A 'lay summary' based on the First International Conference on the Release of Genetically Engineered Microorganisms (REGEM 1), Cardiff, 5-8 April 1988.] B Dixon. (Pp 47; figs; £5 paperback, including UK postage, LS paperback, including UK postage overseas add 50 pence.) Obtainab from Professor A M Paton, University 581 King Street, Aberdeen AB9 IUD. EURO Reports and Studies. No 78 "Indoor Air Pollutants: Exposure and Health Effects." Report on a World Health Organisation Meeting. (Pp 42; Sw frs 4 paperback.) Copenhagen World Health Organisation Region Office for Europe, 1989. ISBN 92 890-1244-7.

\section{Gastroenterology}

Frontiers of Gastrointestinal Research. Vol 15. "Newer Tests and Procedure in Pediatric Gastroenterology. 1. Diagnostic and Therapeutic Procedures." Ed G Dinari, P Rozen, Y Bujanover, E Lebenthal. Series editor P Rozen. (Pp viii +330; figs; £135.) P Rozen. (Pp viii +330; figs; £135.)
Basel: Karger, 1989. Distributed by Basel: Karger, 1989. Distributed by
John Wiley and Sons. ISBN 3-8055-

4646-7.

Frontiers in Gastrointestinal Research. Vol 16. "Newer Tests and Procedures in Pediatric Gastroenterology. 2. Function and Latroenterology." 2. Function and Laboratory Tests." Ed Lebenthal. Series editor P Rozen. (Pp Lebenthal. Series editor P Rozen. (Pp Viiit 296; figs; Ll21.90.) Basel; Wiley and Sons. ISBN 3-8055-4900-8.

\section{Genetics}

The Foundations of Human Genetics. $\mathrm{K}$ R Dronamraju. (Pp xiii +211 ; figs; $\$ 40.75$.) Illinois: Thomas, 1989. ISBN 0-398-05537-8.

\section{Haematology}

Hematology: a Combined Theoretical and Technical Approach. A Simmon. (Pp viii + 423; colour plates; figs; $\$ 25$ paperback.) Philadelphia: Saunders, 1989. Distributed by Harcourt Brace Jovanovich. ISBN 0-7216-1716-6.

Progress in Hemostasis and Thrombosis. Vol 9. Ed B S Coller. (Pp xiv +269 ; figs; 241 .) Philadelphia: Saunders,
1989. Distributed by Harcourt Brace Jovanovich. ISBN 0-7216-2933-4.

Quality Assurance in Haematology. Ed S M Lewis, $\mathbf{R}$ L Verwilghen. (Pp xii + 297; figs; £25.) London: Baillière Tindall, 1988. Distributed by Harcourt Brace Jovanovich. ISBN 07020-1322-6.

\section{Health care issues}

EDI Seminar Paper. No 37. "User Charges for Health Care in Principle and Practice." C C Griffin. (Pp viit and Practice." $\mathrm{C} C$ Griffin. (Pp vil 80 ; $\$ 6.50$ paperback.) Washington
DC; World Bank, 1988. Distributed DC; World Bank, 1988. Distributed in the United Kingdom by Microinfo Ltd., PO Box 3, Alton, Hants
2PG. ISBN 0-8213-1139-5.

Facilitating Change in Mental Health. B Lemmer, M Smits. (Pp xviii +222 figs; $£ 10.95$ paperback.) London: Chapman and Hall, 1989. ISBN 0-41233010-5.

From Alma-Ala to the Year 2000 : Reflections at the Midpoint. World Health Organisation. (Pp vi+158; Sw frs 30 paperback.) Geneva: World Health Organisation, 1988. ISBN 92 4-156124-6.

Mental Health Care in Crisis. Ed A Brackx, C Grimshaw. (Pp viii +216 ; Brackx, C Grimshaw. (Pp viil 216 ,
£14.95.) London: Pluto Press, 1989. ISBN 0-7453-0221-1.

Talking and Listening to Patients: a Modern Approach. C M Fletcher, $\mathrm{P}$ Freeling. (Pp viii $+68 ; £ 2.50$ paperback. London: Nuffield Provincia Hospitals Trust, 1989. ISBN 0900574-70-4.

Therapy in Practice. "Counselling Skills for Health Professionals." Burnard. Series editor J Campling. (Pp xii+201; figs; £10.95 paperback.) London: Chapman and Hall, 1989. ISBN 0-412-32000-2.

\section{History of Medicine}

The British Paediatric Association 1928 1988. J O Forfar, A D M Jackson, B $M$ Laurance. (Pp xix +228 ; figs; 15 including postage.) 1989. Available including postage.) 1989. Available Association, 5 St Andrew's Place, London NW1 4LB.

Resources in Medical History. "An 